\title{
IMPLEMENTING PACKAGED SOFTWARE ${ }^{1}$
}

\author{
by \\ Henry C. Lucas, Jr.* \\ Eric J. Walton** \\ and \\ Michael J. Ginzberg***
}

September 1987

* Information Systems Department

Graduate School of Business Administration

New York University

** University of Western Australia

*** Weatherhead School of Management

Case Western Reserve University

Center for Research on Information Systems

Information Systems Area

Graduate School of Business Administration

New York University

Working Paper Series

CRIS \#162

GBA \#87-81

${ }^{1}$ The research reported in this paper was sponsored by a grant from the UNISYS Corporation. 
IMPLEMENTING

PACKAGED SOFTWARE

\section{$\underline{\text { ABSTRACT }}$}

This paper presents a model of the implementation process for dedicated packages and describes a research project to test the model undertaken with the cooperation of a major computer vendor. Data were collected from 78 individuals in 18 firms using the package and from the package vendor. The results of the study offer some support for the model along with suggestions for package implementation for both the customer and package vendor.

\section{INTRODUCTION}

There have been many problems with the development of information systems in organizations. In particular, the custom design of systems has been associated with cost and schedule overruns and with systems that do not meet user requirements. Evidence suggests that there is a large backlog of applications awaiting development in many organizations.

A number of solutions to difficulties with custom designed systems have been suggested including the use of packaged software. Packages can be classified into two broad categories: general purpose and dedicated. A general purpose package is a tool which a user or systems professional employs to solve a problem. A program like 
Lotus 1-2-3 or an applications generator falls into this category.

A dedicated package offers a solution to the user's information processing problem; the package is dedicated to some particular function like accounts receivable, order entry or production planning. Because the dedicated package is focused on a particular business function rather than being general, an organization adopting the package may have to change its procedures or modify the package. The customer faces a tradeoff between faster implementation and lower cost with a package and more flexibility with a custom developed system.

The purpose of this paper is to describe a study of the implementation process for a packaged system, PS or the Production system. A major computer vendor designed and programmed PS and offers it to its customers. PS consists of multiple, integrated modules with each module dedicated to a different aspect of the manufacturing process. Customers can order all or parts of the package for installation on the vendor's computers.

\section{IMPLEMENTATION}

An increasing body of research on the implementation of information systems has been developed over the last decade; for example, see Schultz and slevin (1975), Docktor, Schultz and Slevin (1979), Lucas (1982) and Schultz and Ginzberg 
(1984) for individual studies and summaries of much of this research.

A significant amount of the work to date has focused on the general problem of implementation for information systems; most of the systems in the literature were custom designed. A few studies, however, have been concerned with the question of package program implementation. Gross and Ginzberg (1984) identified 38 issues as potential obstacles in the acquisition of a package. They reported that a key obstacle to adoption turned out to be uncertainty about package modification time and cost, vendor viability, and the ability of the package to meet user needs. Lynch (1984) argued that financial packages had hidden implementation costs.

As described earlier, the implementation of a dedicated package differs from the implementation of a custom system in several ways:

1. The user may have to change procedures to work with the package.

2. The user is likely to change some of the programs in the package to fit his unique requirements.

3. The user becomes dependent on the package vendor for assistance and for updates to the package.

\section{RESEARCH MODEL}

Figure 1 contains a model of the implementation of packaged software. The model is based on past research and 
the unique characteristics of package implementation described above. The model focuses on two key classes of variables: the implementation process and the success/impact of the package. The model is based on past research (Lucas, 1982) which suggests that certain variables are associated with implementation strategies and that the implementation process is related to the ultimate success of a system. In Figure 1 four classes of variables are expected to be associated with implementation strategies. First, the organization has certain characteristics which are likely to influence its approach to systems. These characteristics include variables like the work environment, the nature of manufacturing technology, and the decisionmaking process. The unique environment of the organization should be important in the firm's approach to implementation.

Second, the potential adopter has certain processing needs which will be important in implementation. If a firm already has a good work-in-process tracking system, a complete production control system may not be of interest. Past research cited earlier suggests that uncertainty over needs is an important barrier to package adoption. Identifying needs and evaluating a package against those needs is an important part of implementation.

A third class of variables consists of the characteristics of the package under consideration. The package is the solution to the users' problems proposed by a vendor. Certain aspects of a package will influence the 
implementation process, especially the functions that it offers. For example, the customer may use modules which support accounting, engineering and materials requirements planning.

There are likely to be discrepancies between the needs of the organization and the features of the package. It is expected that the extent of these discrepancies will influence whether or not the organization decides to acquire a package. If the decision to adopt is positive, the implementation process will require that discrepancies be resolved; either the organization has to change its procedures, compromise on processing needs satisfied, or modify the package.

The implementation process is expected to influence measures of the success and impact of a package. The firm which concentrates on factors associated with implementation success and on the process of implementation should rate the package a success. Discrepancies between the needs of the customer and the features of the package should also be important in determining the success of the package. Much of the installation effort for a package involves the resolution of these discrepancies. Finally, the personal characteristics of employees and their experiences with computers are likely to have an influence on package success. 


\section{RESEARCH DESIGN}

A major computer vendor participated in this research and arranged for data to be collected from its account representatives and customers. The vendor offers the PS system which includes modules for engineering and inventory control, materials requirements planning, work in process control, shop floor data collection, capacity requirements planning, master production scheduling, forecasting, and various accounting applications, among others.

According to the package vendor, 59 clients were using PS. After phoning the vendor's branch offices, the research team sent instruments to 47 clients who were using PS according to branch management. The median firm in the sample manufactures 47 different products and holds about a 40\% market share in its primary market. Products have a median life of 5 years and the firm has six main competitors. The median plant has 225 employees at the location using the package, with 136 of them in the production department.

\section{Instruments}

The research team met frequently with vendor marketing managers and also visited two PS users to discuss their implementation experiences with the package. A set of five questionnaires resulted from this effort. To the greatest extent possible, the questionnaires contain scales used in past research; see (Van de Ven and Ferry, 1980, and Lucas, 
1982). The instruments were pretested at a PS client and a final revision was mailed to vendor representatives. The instruments were to be completed by:

The vendor's account representative, The senior plant manager, The manager of the unit adopting PS, The plant human resources manager, The information systems manager at the plant.

Variables

The instruments each contain a number of questions related to the classes of variables in Figure 1. Related items were combined to form scaled variables or scales were constructed based on their definition in previous studies. Table 1 contains a list of the variables used in the study. The letter subscript in the symbols column indicates the source of the variable as follows:

$M=$ MIS director

$A=$ Adopting unit manager

$\mathrm{V}=$ Vendor representative

$\mathrm{H}=$ Human resource manager

$P=$ Senior plant manager

organization. The first organizational variable is from the plant manager questionnaire; it is an evaluation of how rapidly the plant's manufacturing technology is changing. The next four organizational variables were derived from the adopting unit manager questionnaire and all 
consist of scaled items developed originally by Van de Ven and Ferry (1980).

$\mathrm{O}_{2 \mathrm{~A}}$, unit performance, contains seven items measuring the relative rating of the unit in comparison to other units on performance criteria such as quantity, quality, innovativeness, excellence, goal attainment, efficiency and morale. $\mathrm{O}_{3 \mathrm{~A}}$, dependence on manager, contains three items measuring how much unit personnel depend in their work upon the activities performed by the supervisor.

$\mathrm{O}_{4 \mathrm{~A}}$, task difficulty, contains four items measuring whether incoming work of the unit can be clearly diagnosed and an appropriate method selected to deal with it, as well as whether outcomes of the sequence of steps in the method can be predicted easily.

$O_{5 A}$, supervisory authority, contains four items assessing how much authority the unit supervisor has in relation to the tasks performed in the unit, the criteria for evaluating performance, appraising performance, and establishing mechanisms for coordinating and controlling unit activities. The last organizational variable, $0_{6 M}$, indicates whether or not the firm already had the package vendor's hardware.

Needs. Table 1 shows the variables in the needs category of the research model. $\mathrm{N}_{1 \mathrm{M}}$ is a five-item scale indicating that a number of functions in the accounting and finance area are performed and/or computerized at the plant. $\mathrm{N}_{2 \mathrm{M}}$ is a two-item scale stating that engineering change 
control and product configuration control are done at the plant. The third needs variable, $\mathrm{N}_{3 \mathrm{M}}$, is a single item indicating that MRP is performed at the plant.

Discrepancies. One way to measure the discrepancy between the needs of the user and the solution offered by the package would be to examine customer documents or systems specifications and compare them with package features. Unfortunately, these customer specifications were not available. For the purposes of this study, discrepancies are measured by the degree of modification to the package, both planned and actually undertaken.

$D_{1 M}$ is an estimate from the information systems manager on the extent it was expected the software would have to be modified; this variable is the manager's recollection since the question was asked after installation. The second discrepancy variable measures the extent of software modification. $D_{3 V M}$ is a scaled variable combining the dollar estimates of the vendor representative and the adopting unit manager on the amounts spent to modify the PS software through the vendor. The last discrepancy variable is the same type of scale, only for the amount spent to modify software internally by the customer.

Package Characteristics. The characteristics of the package are all taken from the information services manager questionnaire. $P_{I M}$ is a 16-item scale of the extent to which the package offers support for manufacturing, while $\mathrm{P}_{2 \mathrm{M}}$ is a two-item scale on the extent to which the package 
supports MRP. The next variable, $P_{3 M}$, is a two-item scale reflecting whether or not the client ordered engineering modules.

$\mathrm{P}_{4 \mathrm{M}}$ is a four item scale on whether the client ordered financial and accounting modules. $P_{5 M}$ indicates whether or not MRP modules were ordered. $P_{6 M}$ is an estimate of hardware purchase price while $P_{7 M}$ is an estimate of software purchase price.

Implementation. The implementation variables can be divided into three groups: those related to the requirements analysis and decision to acquire PS, those describing the nature of the customer, and those reflecting the amount of support provided by the PS vendor.

The first variable, $I_{I M}$, is a two-item scale reflecting the involvement of the information systems department in defining system requirements. $I_{2 M}$ is the vendor's participation and influence in installation while $I_{3 M}$, consisting of four items, is the involvement of noninformation systems professionals in the decision on what hardware to acquire.

The variable $I_{4 M}$ is whether the vendor was asked to make a proposal or whether the proposal was unsolicited. $I_{5 \mathrm{M}}$ represents the number of vendors considered besides the PS vendor. The variable $I_{6 M}$ indicates the relative importance of a consultant's recommendation in the selection decisions. $I_{7 M}$ is a five-item scale which reflects the extent to which the PS package was adopted because of the 
features of the software. The extent to which the package was selected based on overall price is represented by variable $I_{8 \mathrm{M}}$.

$I_{9 V}$ is a four-item scale rating the capabilities of the customer as seen by the vendor's representative. I IOV is a similar three-item scale on the representative's rating of the customer's understanding of the package, and $I_{I I M}$ from the MIS manager's questionnaire indicates his assessment of the skills of users.

The support category includes variable $I_{12 \mathrm{~V}}$ which is a five-item scale; for this variable the vendor representative indicated the type of support provided to the customer, for example, through special seminars and in helping to find personnel to run the system. The next variable, $I_{13 M}$, from the MIS manager's questionnaire, rates the extent and importance of installation assistance from the PS vendor; it includes eight items like the use of the vendor's training courses, support from branch office personnel, and support from the package "hot line" maintained by the vendor. $I_{14 \mathrm{M}}$ indicates the extent of ongoing support from the vendor and consists of eight items.

$I_{15 M}$ is a rating of the support in hiring requested from the vendor prior to ordering the system and consists of three items. The last two variables in this category, $I_{16 \mathrm{M}}$ and $I_{17 M}$, reflect the MIS manager's satisfaction with support prior to and during installation, and support after installation, respectively. 
Success/Impact. The first three success variables are satisfaction ratings from the adopting unit manager. The first of these, $S_{1 A}$ is satisfaction with the software purchase price. $S_{2 A}$ is a nine-item scale of satisfaction with software installation and training. $S_{3 A}$ is a sevenitem scale on satisfaction with the characteristics and features of the system.

The last three success measures are from the MIS manager's questionnaire. $S_{4 M}$ represents a rating of satisfaction with system characteristics and features; this scale has seven items. $S_{5 M}$ is a two-item scale on satisfaction with operating and maintenance costs. The last item, $\mathrm{S}_{6 \mathrm{M}}$, is a rating of overall satisfaction with the system. There are also two impact variables, $s_{7 V}$ and $S_{8 V}$, which are estimates from the vendor's representative on the number of new staff needed to maintain and operate the system.

Personal/Background. Variables in this class are basically a given for the implementer. While the variables vary among individuals, they can not be changed over the short term. The first background variable, $B_{1 M}$, is a fouritem scale of previous applications of computers in the plant before the installation of the package. The other two background variables, $B_{2 M A}$ and $B_{3 M A}$, are averages for the MIS manager and adopting unit manager of the number of organizations in which they were previously employed and the number of years they have been working for their current 
firm. (The responses for these two individuals correlated over .9 and were therefore combined for reliability purposes.)

\section{RESULTS}

With a concerted effort, partial or complete responses from 18 firms were finally received in time for analysis, representing a $38 \%$ response rate. The 18 firms provided a total of 78 questionnaires. Several reasons for nonresponse were apparent: some nonrespondents had discontinued the package; for others the package had not been installed long enough for participation; several respondents did not want to participate because of the time required to complete the questionnaires.

The data from the firms were analyzed using nonparametric correlation coefficients. A nonparametric correlation requires less restrictive assumptions than parametric statistics and is well suited to the small sample size of the study. The data tables contain correlations which are significant at the .10 level or better and for which there are at least 13 valid responses.

\section{Organization}

Table 2 contains Kendall correlations between organizational and implementation variables. Faster changing manufacturing technology is positively related to the vendor's ratings of the customer's capabilities, but is negatively related to installation and ongoing assistance 
from the vendor as seen by the MIS manager. Faster changing technology is associated with the vendor being asked for a proposal and with package selection not being based primarily on price. At plants where the manufacturing technology is changing rapidly, the MIS manager sees users as skilled.

Unit performance is negatively associated with involvement in decisions about hardware acquisition by noninformation systems professionals; it is positively correlated with vendor support and negatively related to installation assistance. Unit performance is associated with a request for the package proposal and with selecting a package not primarily on price.

Dependence of the work unit on the adopting unit manager is positively related to the vendor's ratings of customer capabilities, vendor support provided and the MIS manager's satisfaction with support before and after installation of the package. Dependence on the manager is associated with the vendor being requested to make a proposal and with the number of vendors contacted.

Units with more difficult tasks are associated with less skilled users of software who need more installation assistance and have lower capabilities. Units where supervisors have higher authority are associated with less skilled users of software, but receive less support from the vendor. Higher supervisory authority is also correlated with contacting fewer vendors for a proposal. 
Already having the vendor's hardware has a strong negative correlation with the number of vendors contacted by the customer. Having vendor hardware is associated with less input from non Is personnel on the decision and with a lower rating by vendor personnel of the customer's understanding. Having vendor hardware is also negatively related to vendor support and satisfaction with vendor support before and after installation.

\section{Processing Needs}

Table 3 contains the results of correlating variables in the needs category with those in the implementation category. In plants where there are financial and accounting applications on the computer, there is less nonIs influence on the selection of hardware and less vendor support; satisfaction with support is rated higher after installation. These results probably characterize the more mature installation; it has accounting and financial applications on the computer and requires less vendor support.

The presence of engineering at the plant is associated with Is involvement in systems requirements definition, a higher ranking of customer capabilities and more support provided by the vendor. Engineering at the plant is negatively correlated with MIS managers' satisfaction with vendor support after installation.

Having MRP performed in the organization is associated with higher ratings of the capabilities of the client and 
his understanding of the system by the vendor and higher ratings of user skills by the MIS manager. MRP at the plant is related to contacting fewer vendors for a proposal and with less influence from price in selecting a system.

\section{Package}

Table 4 presents the results of correlating package and implementation variables. High ratings of manufacturing support from the system are associated with less Is involvement in requirements analysis, higher user skills, and more ongoing assistance from the vendor. Manufacturing support is also associated with recommendations on the package from a consultant and high satisfaction with support before and after installation.

Support for MRP from the package is negatively related to vendor participation and client understanding. It is positively correlated with the importance of a consultant's recommendation and satisfaction with support prior to installation.

ordering the engineering modules is positively associated with non-Is involvement in the hardware decision, client understanding, installation and ongoing assistance, and before-installation satisfaction with the vendor. ordering financial and accounting software is negatively related to IS involvement The influence of non-IS personnel in choosing hardware and installation assistance are positively correlated with ordering the financial and accounting modules. 
ordering MRP modules is positively related to ratings of client capabilities and the ongoing assistance provided by the vendor.

Higher estimated hardware costs is associated with less input from non-IS personnel on hardware and a higher rating of client capabilities by the sales representative. Higher estimated hardware cost is associated with asking the vendor for a proposal, relying less on a consultant's recommendations and in not selecting the package on price. There is a negative correlation for estimated hardware cost with ongoing assistance and a positive one with support requested.

A higher estimated software cost is associated with lower IS and vendor participation in decisionmaking. Higher software price is associated with the Is manager rating user skills as lower and with the client asking for and the vendor providing more support.

\section{Discrepancies}

In Table 5 higher expectations to modify the package are associated with higher ratings of client capabilities by the vendor's representatives and higher ratings of user skills by the Is manager. Surprisingly higher expectations are associated with lower levels of installation assistance and greater satisfaction with support prior to installation. The extent of actual modifications reported by the MIS manager is positively related to the vendor's rating of the client's capabilities, and support requested of and provided 
by the vendor. Greater modifications are related to higher satisfaction with support prior to and during installation. The extent of actual modifications is associated with asking the vendor for a proposal and with contacting a larger number of vendors.

Higher costs of vendor modification are associated with greater vendor participation in installation and with lower ratings of the client's capabilities by the vendor. Vendor support and installation assistance are positively associated with payments to the vendor for modifications. This type of expenditure is also associated positively with support requested. The picture here is of the less capable client drawing heavily on the vendor to modify the package. Spending more internally for package modification is associated with lower levels of vendor participation in installation, the customer contacting more vendors and relying less on a consultant's recommendations. Internal spending is positively related to higher ratings of the capabilities of the client by the vendor. Requested support is highly and positively correlated with internal modifications, possibly because the client needs input from the vendor to make changes in the system. The data suggest that the more capable client tends to make the modifications himself, though help from the vendor is still needed. Success/Impact

Implementation. Table 6 contains the correlation of success and impact variables with implementation variables. 
More Is involvement in setting requirements is associated with higher estimates of staff to operate the system. Greater vendor participation in installation is associated with higher levels of satisfaction with system features and with higher estimates of staff to maintain and operate the system.

Requesting a proposal from the vendor is negatively related to satisfaction with operating and maintenance costs and with estimates of staff needed to maintain the system. However, contacting more vendors is positively related to these two variables! Attaching more importance to a consultant's recommendation is associated with higher estimates of operations staff.

Making a decision based on the software is associated with satisfaction with system features. The importance of price in selecting the package is negatively related to satisfaction with features, with operating/maintenance costs, and overall satisfaction.

A high rating of customer capabilities by the vendor is associated with satisfaction with software installation and overall satisfaction. Greater levels of customer understanding as rated by the vendor are associated with lower estimates for additional staff to maintain and operate the system.

High user skills as rated by the MIS manager are positively and strongly associated with satisfaction; five out of six possible correlations are significant. Higher 
levels of vendor support are negatively related to satisfaction with the purchase price of the software and positively related to the vendor's estimate that new staff will be needed to operate and maintain the system.

Assistance with installation is positively related to satisfaction with system features and with estimates of additional operating staff. Requested support is negatively related to satisfaction with the software price and positively related to overall satisfaction.

The MIS manager's ratings of support just before installation are not significantly correlated with any of the success measures. Support after installation is positively associated with MIS manager satisfaction with features, satisfaction with operating and maintenance costs and with overall satisfaction.

Discrepancies. Table 6 presents the correlation of discrepancy variables and success/impact variables. Expectations to modify are negatively related to the MIS manager's satisfaction with operating and maintenance costs. The extent of modifications is negatively related to the adopting unit manager's satisfaction with software price. Changes are positively correlated with satisfaction with software installation and estimates of additional staff to maintain the system.

The amount spent on vendor modifications is negatively associated with the adopting unit manager's satisfaction with software price and is positively related to the 
estimated need for additional maintenance staff. The amount spent internally on modification is unrelated to satisfaction variables.

Background/Personal. Table 6 also contains the three background and personal variables correlated with success and impact variables. The prior use of computers at a plant is positively and highly correlated with satisfaction as are the respondent's years worked at the firm. Years worked at the firm is negatively related to the need for more staff. Respondents with more experience in other organizations have lower satisfaction with the package in general, but higher satisfaction with the price of the software. Individuals who have worked other places have probably seen more systems, are aware of other ways to operate, and have more experience with information systems. They may tend to judge the PS package more harshly as a result of their prior experience and contact with other hardware, software and vendors.

\section{IMPLICATIONS}

The primary limitation with this study is the small sample size in number of companies, although there are 78 responses from different individuals. The results, however, do show significant relations among different individuals' reactions to the PS package. The fact that variables come from independent participants in the study increases confidence in the results. 


\section{Findings}

The variables in the success/impact class are used in this study to evaluate the outcome of the PS package implementation. It is interesting to note how strongly the prior use of computers correlates with satisfaction measures as does greater length of service by respondents. These results suggest that experience does in fact help in package implementation. Results also indicate that experience in a number of other firms may create skepticism or heighten expectations resulting in lower levels of satisfaction with a package.

Higher levels of modifications to the package are negatively associated with satisfaction with the price of the software. Organizations often estimate that the cost of a package is the price quoted by the vendor. In fact, this cost may turn out to be a rather small component of the overall cost of a project when modifications and the efforts of customer employees are included. A package vendor might improve the implementation process and satisfaction with it by providing the customer with a more realistic estimate of costs to create more accurate expectations. On the other hand, such an assessment might make a package less attractive to a potential customer.

The MIS manager's ratings of users skills was strongly correlated with satisfaction measures. The vendor's ratings of customer capabilities is also positively related to success. While causality cannot be demonstrated with this 
type of research design, the data suggest that a highly skilled work force will be more successful in package implementation. The vendor's participation in installation and support for the project are also associated with satisfaction. Satisfaction with vendor support after installation is highly correlated with the success/satisfaction variables in Table 6 , much more than is satisfaction with vendor support before installation.

From the results of this study, it appears that the resolution of discrepancies between user needs and the package will require significant vendor support and assistance. This finding may reflect on the package's design and the need to tailor manufacturing applications. The results also show that more modifications and more vendor support are also associated with dissatisfaction with price. Interestingly, customers rated highly by the vendor tend to do their own modifications.

Approaching more than one vendor is associated with greater satisfaction as is requesting bids. Organizations which already had the vendor's hardware tended not to look at other vendors, were rated as having less capable staff by the vendor and tended to receive less support before and after installation. Firms investigating a package are well advised to take advantage of the differences among vendors to find the software package which best suits their needs. The importance of price in selecting a vendor is negatively associated with three satisfaction variables. 
Given the large investment required for acquiring and installing a major package, it appears unwise for customers to be too sensitive to the advertised price of the package, particularly given the cost of modifications and the cost to the customer for training and installation.

\section{The Model}

The model receives some support from this research. Personal/background and implementation variables do seem to be associated with measures of package success while discrepancies are related more to implementation. There is some support for the role of discrepancies in the implementation process and the demands that discrepancy resolution place on the vendor for support. Package and needs variables are associated with implementation variables. Characteristics of the organization such as the nature of tasks, performance, and the unit manager's influence and support also relate to some of the implementation variables.

The number of relationships obtained between sets of variables in the model exceed those expected by chance alone. However, more research on a larger sample of firms is necessary to further evaluate the model. Future efforts should explore more fully the role of discrepancies and should attempt to find variables which actually reflect the differences between the package's features and user needs. 


\section{Recommendations}

While the findings of this research must be viewed as tentative, what actions do the model and results suggest for a customer and package vendor if the findings are valid? The customer should undertake a requirements analysis, at least at a high conceptual level, so that it is possible to identify discrepancies between a package and user needs prior to making a commitment to a package. The customer should also contact multiple vendors and should not necessarily choose the package because their current hardware vendor sells it or because it has a low "base" price.

If the customer does not have knowledge of the functions supported by the package, it would be advisable to hire or train individuals who do. For example, for the PS package a firm could enroll potential users in courses on MRP. The customer should count on having to make modifications in dedicated packages, though he should also consider the alternative of changing existing procedures to avoid the high cost and delays of changing the package.

The package vendor needs to work closely with the client in comparing the package to customer needs. After jointly identifying discrepancies, the two parties should estimate the extent of modifications necessary and their cost.

The package vendor must be prepared to offer substantial support for the customer when selling a 
dedicated package. In particular, the vendor may want to evaluate the capabilities of the client and recommend special education or consulting help to prepare for package installation. These assessments of clients' expertise, support and installation assistance provided by the vendor are most clearly related to characteristics of the client's work environment, tasks and technology, and decisionmaking process. These organizational features provide clues as to client experience and subsequent needs for support. In providing this support, the vendor may want to calculate and include the cost of sufficient consulting help for each customer in its bid.

\section{CONCLUSIONS}

This paper has reported a study of packaged software implementation. The research model receives some support from the data, though the sample size is small. Dedicated software packages remain one of the most promising solutions to reducing the applications backlog, but their implementation is critical to the ultimate success of this approach to systems development.

This paper suggests a package implementation strategy which focuses on the discrepancies between a user's requirements and the package, and on formulating a plan to resolve those discrepancies. Simultaneously, the client and vendor should work to develop a capable and skilled 
workforce to prepare for package installation in particular work environments.

Vendors now propose that a package is a "problem solution," something that consists of more than just software. The customer is buying software, possibly hardware, and vendor expertise. The suggestions arising from this research are that the "solution" should come with an implementation strategy which recognizes the challenges of implementing packaged software.

\section{REFERENCES}

Doktor, R., R. L. Schultz and D. P. Slevin (eds.), The Implementation of Management Science, Amsterdam: North-Holland, 1979.

Gross, P., and M. J. Ginzberg, "Barriers to the Adoption of Application Software Packages," SOS, Vol. 4, No. 4, (1984), pp. 211-226."

Lucas, Henry C., Jr. Implementation: The Key to Successful Information Systems. New York: Columbia University Press, 1982 .

Lynch, R.K., "Implementing Packaged Application Software: Hidden Costs and New Challenges," SOS, Vol. 4 No. 4, (1984), pp. 227-234.

Schultz, R. L. and M. J. Ginzberg, Management Science Implementation, Supplement 1 to Applications of Management Science, Greenwich, Connecticut: JAI Press, 1984 .

Schultz, R. L. and D. P. Slevin (eds.) Implementing operations Research/Management Science, New York: American Elsevier, 1975.

Van de Ven, A. H., and D. L. Ferry. Measuring and Assessing organizations. New York: John Wiley and Sons, 1980. 
TH E R E S E A R C H MO D E L

F I G U R E 1

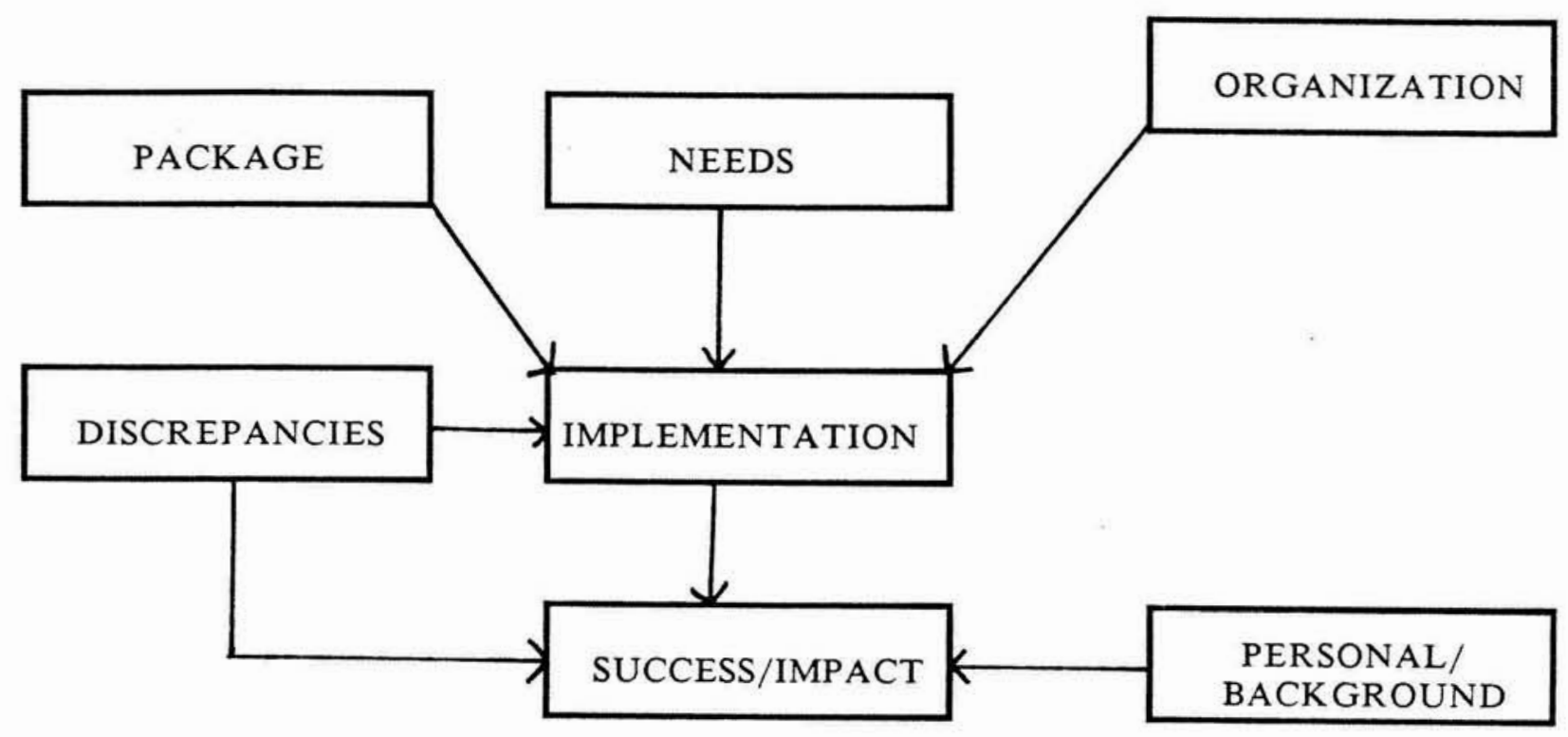


VARIABLES IN THE STUDY

T A B L E 1

SYMBOL

ORGANIZATIONAL

$0_{1 P}$

$\mathrm{O}_{2 \mathrm{~A}}$

$\mathrm{O}_{3 \mathrm{~A}}$

$\mathrm{O}_{4 \mathrm{~A}}$

$\mathrm{O}_{5 \mathrm{~A}}$

${ }^{0} \mathrm{M}$

NEEDS

$\mathrm{N}_{1 \mathrm{M}}$

$\mathrm{N}_{2 \mathrm{M}}$

$\mathrm{N}_{3 \mathrm{M}}$

DISCREPANCIES

$\mathrm{D}_{1 \mathrm{M}}$

$\mathrm{D}_{2 \mathrm{M}}$

$D_{3 V M}$

$\mathrm{D}_{4 \mathrm{VM}}$

PACKAGE

$P_{1 M}$

$\mathrm{P}_{2 \mathrm{M}}$

$\mathrm{P}_{3 \mathrm{M}}$

$\mathrm{P}_{4 M}$

$\mathrm{P}_{5 \mathrm{M}}$

$\mathrm{P}_{5 \mathrm{M}}$

$\mathrm{P}_{7 \mathrm{M}}$
How rapidly manufacturing technology is changing

Unit performance

.91

Dependence of work unit on adopting manager $\quad .86$

Task difficulty $\quad .81$

Authority of manager on immediate subordinates

Already had vendor's hardware

Financial/accounting performed on a computer

.76

Engineering functions at plant

.69

MRP performed

Extent expected it would be necessary to modify software

Extent of changes to software

Amount spent to modify software through vendor 092

Amount spent to modify internally

.60

System provides support for manufacturing $\quad .85$

$\begin{array}{ll}\text { System provides support for MRP } & .95\end{array}$

Ordered engineering modules $\quad .75$

Ordered financial/accounting modules $\quad .96$

Ordered MRP modules

Estimated hardware purchase price

Estimated software price 
TABLE1- CONTINUED

\section{IIPLWMENTATION}

Decision

$\mathrm{I}_{1 \mathrm{M}}$

$I_{2 \mathrm{M}}$

$I_{3 \mathrm{M}}$

$I_{4 \mathrm{M}}$

$I_{5 M}$

$I_{6 M}$

$I_{7 M}$

$I_{8 M}$

Customer

$I_{9 \mathrm{~V}}$

$I_{10 \mathrm{~V}}$

$I_{11 \mathrm{M}}$

Support

$I_{12 \mathrm{~V}}$

$I_{13 \mathrm{M}}$

$I_{14 \mathrm{M}}$

$I_{15 \mathrm{M}}$

$I_{16 \mathrm{M}}$

$I_{17 \mathrm{M}}$

SUCCESS

Satisfaction

$\mathrm{S}_{1 \mathrm{~A}}$

$\mathrm{S}_{2 \mathrm{~A}}$

$\mathrm{S}_{3 \mathrm{~A}}$

$\mathrm{S}_{4 \mathrm{M}}$

$\mathrm{S}_{5 \mathrm{M}}$

$\mathrm{S}_{6 \mathrm{M}}$

Impact

${ }^{5} 7 \mathrm{~V}$

$\mathrm{S}_{8 \mathrm{~V}}$

PERSONAL/BACKGROUND

$B_{1 \mathrm{M}}$

$B_{2 M A}$

$\mathrm{B}_{3 \mathrm{MA}}$
IS involvement in systems requirements

.81

Vendor's participation/influence installation

Non IS involvement in hardware decision

.67

Vendor asked (0) or unsolicited proposal (1)

Number of vendors considered other than one chosen

Consultant recommended vendor's package

Chose due to features of software

84

Selected due to price

Capabilities of customer

.83

Customer understanding of package

.78

Users have skills; need no training

Extent of vendor support

.94

Extent of installation assistance

.91

Ongoing assistance from vendor

.89

Support requested from vendor

.94

Satisfaction with vendor's support before installation

Satisfaction with vendor's support after installation
Satisfaction with software purchase price

Satisfaction with software, installation, training

.93

Satisfaction with system's characteristics, features

.93

Satisfaction with system's characteristics, features

.87

Satisfaction with operating and maintenance costs

.57

Overall satisfaction with system

Estimated new staff to maintain system

Estimated new staff to operate system
Previous applications of computers in plant before package .85 Number of organizations in which previously emplc

Years working full-time
Center for Digital Economy Research 
TABLE 2

\begin{tabular}{|c|c|c|c|c|c|c|}
\hline & $0_{1 P}$ & $\mathrm{O}_{2 \mathrm{~A}}$ & $0_{3 A}$ & $\mathrm{O}_{4 \mathrm{~A}}$ & $0_{5 \mathrm{~A}}$ & ${ }^{0} 6 \mathrm{M}$ \\
\hline Implementation & $\begin{array}{l}\text { Changing } \\
\text { Manufacturing } \\
\text { Technology }\end{array}$ & $\begin{array}{c}\text { Performance } \\
\text { Unit }\end{array}$ & $\begin{array}{l}\text { Depend } \\
\text { on } \\
\text { Manager }\end{array}$ & $\begin{array}{c}\text { Task } \\
\text { Difficulty }\end{array}$ & $\begin{array}{c}\text { Authority } \\
\text { of } \\
\text { Manager }\end{array}$ & $\begin{array}{l}\text { Vendor's } \\
\text { Hardware }\end{array}$ \\
\hline
\end{tabular}

$I_{1 \mathrm{M}}$ IS Involvement

$I_{2 \mathrm{M}} \quad$ Vendor Participation

$I_{3 M} \quad$ Non IS Hardware

*50

(13)

$\begin{array}{ccc}* * & * * & * * \\ -60 & -69 & -51 \\ (13) & (14) & (14)\end{array}$

$I_{5 \mathrm{M}}$ Number of Vendors

$$
-43
$$$$
\begin{array}{r}
* \\
-38
\end{array}
$$

(13)

****

(14)

$I_{10 M}$ Understanding

$I_{11 M}$ User Skills Software

**

(14)

$I_{12 \mathrm{~V}}$ Vendor Support

$I_{13 \mathrm{M}}$ Installation Assistance

$-41$

(13)
**

(13)
(14)

$-43$

(14)

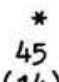

(14)

$I_{14 M}$ Ongoing Assistance Support

$I_{15 \mathrm{M}}$ Support Requested

$I_{16 \mathrm{M}}$ Support Before

*51

(15)

$-51$

4)

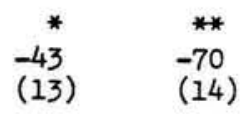

$\begin{array}{cc}* & * \\ 39 & -42 \\ (14) & (13)\end{array}$

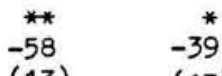

(13) (13)

*

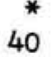

(13)

$I_{17 M}$ Support After

$-50$

(15)

**

$-49$

Kendall correlation coefficient X 100

$$
\begin{array}{rl}
* & \mathrm{p}<.10 \\
* * & \mathrm{p}<.05 \\
* * & \mathrm{p}<.01
\end{array}
$$


NEEDS VERSUS IMPLEMENTATION RESULTS

TABLE 3

\section{Implementation}

$I_{1 \mathrm{II}}$ IS Involvement

$I_{2 M}$ Vendor Participation

$I_{34}$ Non IS Hardware

$I_{4 M} \quad$ Vendor Proposal

$I_{5 \mathrm{M}} \quad$ Number of Vendors

I 6 Consultant Recomm.

$I_{7 M} \quad$ Chose on Software

I 8 Select on Price

$I_{9 V} \quad$ Capabilities

I IOV Understanding

$I_{11 \mathrm{M}} \quad$ User Skills Software

I $12 \mathrm{~V} \quad$ Vendor Support

I 13M Installation Assistance

$I_{14 M} \quad$ Ongoing Assistance Support

$I_{15 \mathrm{M}} \quad$ Support Requested

$I_{16 \mathrm{M}} \quad$ Support Before

$I_{17 \mathrm{M}}$ Support After

Kendall correlation coefficient X 100
NEEDS

$\mathrm{N}_{1 \mathrm{H}}$
Fin/Acct
on Computer

on Computer

**

(15)

\begin{tabular}{cc}
$\mathrm{N}_{2 \mathrm{I}}$ & $\mathrm{N}_{3 \mathrm{H}}$ \\
$\begin{array}{c}\text { Engineering } \\
\text { at Blant }\end{array}$ & $\begin{array}{c}\text { MRP } \\
\text { Performed }\end{array}$ \\
\hline
\end{tabular}

*

41

(15)
**

$-42$

(16)
37

(15)

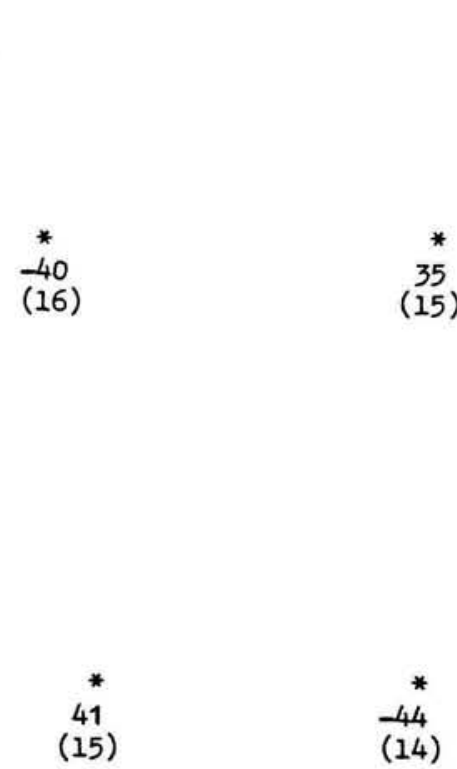

35

15)
(15)
(14)

$-49$

**

(16)

*

40

*

(17) 
PACKAGE \& IMPLEMIENTATION RESULTS

TABLE 4

Implementation

$I_{1 M}$ IS Involvement

$P_{\text {1I }}$

Mfg.

Support

$I_{2 M}$ Vendor Participation

$I_{3 M}$ Non IS hardware

$I_{4 M}$ Vendor Proposal

$I_{5 \mathrm{M}} \quad$ Number of Vendors

$I_{6 M}$ Consultant recomm.

$I_{7 M}$ Chose on Software

$I_{8 M}$ Select on Price

$I_{9 V}$ Capabilities

$I_{10 \mathrm{~V}}$ Understanding

$I_{11 \mathrm{M}}$ User Skills

$I_{12 \mathrm{~V}}$ Vendor Support

$I_{13 \mathrm{M}}$ Installation

Assistance

$I_{14 \mathrm{M}}$ Ongoing Assistance Support

$I_{15 \mathrm{M}}$ Support Requested

$I_{16 \mathrm{M}}$ Support Before

$I_{17 \mathrm{M}}$ Support After
*

$-44$

(14)

51

(14)

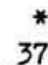

(14)

\begin{tabular}{ll}
$P_{2 M}$ & $P_{3 H}$ \\
MRP & $\begin{array}{l}\text { Engineering } \\
\text { Support }\end{array}$ \\
& Ordered \\
\hline
\end{tabular}

Support

*

(15)

*

(15)

**

(15)

**

(13)

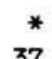

(15)

44

(16)

**

50

(14)

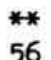

(14)

**

(14)

PACKAGE

$\mathrm{P}_{4 \mathrm{AI}}$

Fin/Acet

Ordered

$* *$
-48

(16)

35

(15)
$P_{5 \%}$

MRP

Ordered
${ }_{6 \mathrm{H}}$

Est. Hardware Cost
${ }^{\mathrm{P}} 7 \mathrm{H}$

Est. Soft-

ware Cost

**

(14)

$-40$

(13)
$-50$

(14)

$-48$

(15)

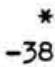

(14)
$-37$

(15)

**

(17)
*

(15)
* *

(15)

**

47

(14)

*

(16) $\begin{array}{cc}* & * * \\ 41 & -56 \\ (15) & (14)\end{array}$

41

(15)
4 范

(14)

Kendall correlation coefficient X 100

$$
\begin{aligned}
& \text { * } \quad \mathrm{p}<.10 \\
& \text { ** } \quad \mathrm{p}<.01
\end{aligned}
$$


TABLE 5

\begin{tabular}{|c|c|c|c|}
\hline \multicolumn{4}{|c|}{ DISCREPANCIES } \\
\hline$D_{1 M}$ & $\mathrm{D}_{2 \mathrm{M}}$ & $D_{3 V M}$ & $\mathrm{D}_{4 \mathrm{VM}}$ \\
\hline $\begin{array}{l}\text { Expected } \\
\text { to Modify }\end{array}$ & $\begin{array}{l}\text { Extent of } \\
\text { Modification }\end{array}$ & $\begin{array}{c}\text { Spent } \\
\text { on Vendor }\end{array}$ & $\begin{array}{l}\text { Spent } \\
\text { Internally }\end{array}$ \\
\hline
\end{tabular}

Implementation

$I_{1 M}$ IS Involvement

$I_{2 M}$ Vendor Participation

$I_{3 M}$ Non IS Hardware

$I_{4 M}$ Vendor Proposal

$I_{5 M} \quad$ Number of Vendors

$I_{6 M}$ Consultant Recomm.

$I_{7 M} \quad$ Chose on Software

$I_{8 M}$ Select on Price

$I_{9 \mathrm{~V}}$ Capabilities

$I_{10 \mathrm{~V}}$ Understanding

$I_{11 M}$ User Skills

$I_{12 \mathrm{~V}}$ Vendor Support

$I_{13 M}$ Installation Assistence

$I_{14 M}$ Ongoing Assistance

I $_{15 \mathrm{M}}$ Support Requested

$I_{16 \mathrm{M}}$ Support Before

50 * ${ }^{*}$

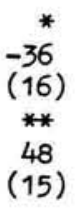

(15)

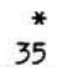

(16)

**

$-52$

(15)

*

(16)

*

$-33$

37
$(15)$

(17)

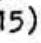

$\begin{array}{cc}* * * & * * \\ 58 & 46 \\ (15) & (17) \\ & * * \\ & 56 \\ & (16)\end{array}$

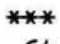

64

(16)

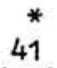

(16)

43

(15)
**

52
$(15)$

$I_{17 \mathrm{M}}$ Support After

Kendall correlation coefficient X 100

$$
\begin{array}{rl}
* & \mathrm{p}<.10 \\
* * & \mathrm{p}<.05 \\
* * & \mathrm{p}<.01
\end{array}
$$


Implementation

$I_{1 \mathrm{M}}$ IS Involvement

$\mathrm{I}_{2 \mathrm{M}}$ Vendor Participation

$I_{3 M}$ Non IS Hardware

$I_{4 M}$ Vendor Proposal

$I_{5 \mathrm{M}}$ Number of Vendors

${ }^{16 M}$ Consultant Recomm.

$I_{7 \mathrm{M}}$ Chose on Software

$I_{8 M}$ Select on Price

Iq Capabilities

$I_{10 V}$ Understanding

$I_{11 M}$ User Sk11ls Software

$I_{12 V}$ Vendor Support

$I_{13 M}$ Installation Assistance

$I_{1 / 4 \mathrm{M}}$ Ongoing ABistance

I $_{15 \mathrm{~K}}$ Support Requested

$-48$

(14)

$I_{16 M}$ Support Before

$I_{17 \mathrm{M}}$ Support After

\section{D1screpancies}

$D_{1 M}$ Expected to Modify

$D_{2 M}$ Extent of Modification

$D_{3 M} \quad$ Spent on Vendor

$D_{4 \mathrm{VM}}$ Spent Internally

Background/Personal

$B_{1 H}$ Prior Use

$B_{2 M A}$ Number Organizations

$B_{3 M \Lambda}$ Years Morked

\section{$s_{11}$ \\ $\mathrm{S}_{2 \mathrm{~A}}$ \\ $s_{31}$ \\ Satiafaction \\ Satisfaction Satiafaction \\ Operating/}

Satisiaction

Sof tware

Features Maintenance Costs

Featurcs \begin{tabular}{ccc}
$S_{G H}$ & $S_{7 v}$ & $S_{B V}$ \\
& Stafr & Starf \\
Overall & to & to \\
Satisfaction & Maintain & Operate \\
\hline
\end{tabular}

44

(15)

$4 i^{*}$

(15)

43 $\quad 61$
-6
" 70

(13)

$40^{\circ}$

(13) (13)
$-55$

(15)

42

(14)

41

(15)

$-36$

(15)

(13)

(15)

(15)
“㩆

(15)

(15)
39

(14)

(15)

荡

(15)

48

(15)

$4 \frac{7}{3}$

(14)

$-4 i^{*} \quad-51$

(15) (15)

- 67

(15)

$\begin{array}{cc}*{ }^{*} & \\ (17) & (17) \\ & \\ & 35 \\ & (15)\end{array}$

39

(15)

$\begin{array}{lcc}57 & 43 & 53 \\ (15) & (15) & (15)\end{array}$

$-39$

(15)

37

(13)

39

(15)

(17)

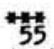

(15)

35

(16)

$-56 \quad-51$

粗范

(13) (15)

(15) (16)

57

(15)

58

(14)
*⿻一⿻口卄日乀

(15)
39

(15)
$-67 \quad-53$

(16) (16) 